\title{
STRATEGI HUMAS PEMERINTAH KOTA SURAKARTA DALAM MEMPUBLIKASIKAN SIPA MAHASWARA
}

\author{
Tiffany S. Mahendra, Jaya Purnawijaya \\ STIKOM LSPR Jakarta \\ jaya.p@lspr.edu
}

\begin{abstract}
Pemerintah Kota (Pemkot) Surakarta untuk menjadikan sebagai kota budaya melakukan banyak kegiatan yang bernuansa seni-budaya. Salah satunya adalah Solo International Performing Art (SIPA), diadakan tiap tahun sejak 2009. SIPA Mahaswara adalah pagelaran ke 8 yang dilaksanakan Tahun 2016. Humas Pemkot Surakarta memiliki strategi untuk mensukseskan acara tersebut. Strategi yang dilakukan menggunakan berbagai macam media publikasi seperti media online dan media cetak. Penelitian ini menggunakan metode kualitatif melalui wawancara, observasi, dan penelusuran dokumen. Analisis data menggunakan Miles \& Huberman, menemukan hasil bahwa Humas Pemkot Surakarta melakukan publikasi secara keseluruhan terhadap kegiatan SIPA. Dalam hal publikasi SIPA Mahaswara, pihak Pemkot Surakarta menggunakan berbagai media seperti brosur, leaflet, poster, flyer, media internal, dan press release. Media internal yang digunakan terdiri dari beberapa macam media seperti media sosial baik milik Humas Pemkot Surakarta, Dinas Pariwisata dan SIPA, buku calender of event dan papan pengumuman yang diletakan di hotel-hotel yang ada di Solo, website baik dari Pemkot Surakarta dan SIPA, serta aplikasi solo destination yang hanya dapat diunggah di android.
\end{abstract}

Kata Kunci : strategi komunikasi, publikasi, media publikasi,, sipa mahaswara.

\begin{abstract}
There are so many activities about art and culture to make Surakarta's City Government as a city of culture. One of the activities is Solo International Performing Art (SIPA) Mahaswara which was held in 2016. In order to be successful, Surakarta's City Government used a strategy to publicize their event. Pemkot Surakarta used online media and printed media for their PR strategy. In this study, the researcher uses gualitative method by interview and observation. From analysis using Miles \& Huberman, Public Relations of Surakarta's City Government publicized all information about activities that were held by City Government. Publicity for each event was performed by the executor SIPA and coordinated by Dinas Pariwisata Surakarta. So, Surakarta's City Govenrment conducted publicity in general, and technically, details of the publication activities are carried out by SIPA as executor.
\end{abstract}

Keywords: strategic communication, publication, media publication, sipa mahaswara. 


\section{PENDAHULUAN}

Pemerirah Kota Surakarta pada tahun 2009 menggelar sebuah kegiatan yang diberi tajuk Solo International Performing Art (SIPA) dengan tujuan untuk mengenalkan Solo sebagai kota budaya,. SIPA adalah sebuah ajang pergelaran seni pertunjukan yang berisikan materi seni tari, musik, dan teater. Event SIPA ini digagas oleh Wali Kota Solo, yang pada saat itu dijabat Joko Widodo .(antaranews.com, 2009, Mansy, Agustus 11).

SIPA dalam perkembangannya, terus mencari berbagai bentuk sampai menemukan bentuk terbaiknya seperti sekarang ini. Namun, satu hal yang tidak akan ditinggalkannya adalah spirit Solo menjadi ajang interaksi budaya untuk menguatkan konsep Solo sebagai Kota Budaya. Inilah yang akan selalu menjadi semangat dari proses pencarian bentuk ideal dari SIPA.

Kegiatan SIPA telah berjalan 8 kali penyelenggaraan sejak Tahun 2009, dan pada Tahun 2016 penyelenggaran SIPA diadakan pada tanggal 8-10 September di Benteng Vastenburg Kota Solo dengan tema Mahaswara. Tema Mahaswara memiliki makna untuk menyampikan pesan kemanusiaan yang akan ditebarkan melalui keindahan seni pertunjukan berbagai bangsa dari penjuru dunia. Dunia membutuhkan suara atau swara, apalagi yang menyangkut dengan suara kemanusiaan; seperti tentang perdamaian, pelestarian alam, dan persahabatan. Melalui SIPA 2016, spirit Maha Swara akan diungkapkan melalui seni pertunjukan khususnya tari, dan musik, sehingga dapat dibayangkan bagaimana kemegahan dan keindahan Maha Swara itu ketika berada dalam panggung SIPA (sipafestival.com).

Kegiatan SIPA 2016 tersebut telah berhasil menghadirkan 22 delegasi peserta yang berasal dari seniman internasional, nasional, dan local untuk mengisi acara. Seminan internasional dihadirkan dari Korea, Spanyol, Singapore, Zimbabwe, USA, India dan Malaysia. Seniman nasional dihadirkan dari Yogyakarta, Jakarta, Medan, Palu, dan peserta lokal dari Solo yang menjadi tuan rumah.

Penyelenggaraan kegiatan SIPA yang telah berlangsung selama 8 tahun berturut-turut sejak tahun 2009 ini tentunya tidak akan berhasil jika tidak ada peran dari Pemkot Surakarta. Dengan menggunakan strategi komunikasi yang tepat Pemkot Surakarta mampu mengenalkan acara SIPA tersebut sehingga dapat diketahui oleh warga masyakarakat luas.

Pada dasarnya strategi merupakan hal yang penting karena strategi atau perencanaan adalah salah satu fungsi manajemen yang harus dilalui oleh setiap fungsi bisnis dalam suatu organisasi, termasuk fungsi pendukung berupa komunikasi. Perencanaan dibuat bertujuan untuk mencapai hasil yang diinginkan, yakni efektivitas komunikasi. Kegiatan 
komunikasi dapat dikatakan efektif bila terjadi pemahaman antara komunikator dan komunikan. Setelah adanya pemahaman, maka komunikan akan percaya (trust) kepada komunikator (kemenkeu.go.id, 2015, Wiyanto, Oktober 1).

Menurut Hafied Cangara (2014) berdasarkan model komunikasi yang ada, tahapan penetapan stategi komunikasi diawali dengan tahap penemuan (identifikasi) dan penetapan masalah serta menetapkan tujuan yang ingin dicapai. Setelah itu dilanjutkan dengan tahapan penetapan strategi komunikasi itu sendiri seperti: penentuan komunikator, penetapan target sasaran dan analisis kebutuhan khalayak, penyusunan pesan, pemilihan media, produksi media, uji awal materi komunikasi (pretesting communication material), penyebarluasan pesan, pengaruh yang diharapkan, mobilisasi sumber daya luar, penetapan anggaran belanja, penentuan jadwal kegiatan, tim kerja, evaluasi (post testing). Strategi komunikasi yang direncanakan dan dilaksanakan tersebut bertujuan untuk menciptakan suatu aktivitas komunikasi yang efektif.

Tentunya dalam strategi komunikasi ada tujuan yang ingin dicapai melalui suatu kegiatan yang dapat menjadi media penyampaian pesan kepada publik. Dalam penelitian ini kegiatan komunikasi yang dimaksud adalah publikasi. Yang dimaksud dengan publikasi di sini berasal dari kata "publicare" yang berarti "untuk umum". Jadi publikasi adalah suatu kegiatan untuk mengenalkan organisasi atau perusahaan, sehingga umum (publik dan masyarakat) dapat mengetahuinya (adhistiararoes.wordpress.com, Roes, 2013, November 19).

Penelitian ini ingin mengetahui lebih dalam bagaimana strategi Humas Pemkot Surakarta mempublikasikan SIPA Mahaswara dengan menggunakan model strategi komunikasi. Adapun tujuan penelitian ini untuk menganalisis strategi Humas Pemkot Surakarta dalam mempublikasikan SIPA Mahaswara.

\section{TINJAUAN PUSTAKA}

Menurut Lasswell dalam buku Mulyana menyebutkan terdapat 5 (lima) unsur komunikasi yang saling bergantungan satu sama lain, yaitu : (a). Sumber (Source). Individu, kelimpok, organisasi, perusahaan, atau negara yang berinisiatif atau mempunyai kebutuhan untuk berkomunikasi, (b) Pesan. Seperangkat simbol verbal dan atau nonverbal yang dikomunikasikan oleh sumber kepada penerima, (c) Media atau saluran. Alat atau wahana yang digunakan sumber untuk menyampaikan pesannya kepada penerima, (d) Penerima (receiver). Sering juga disebut sasaran/tujuan (destination), komunikate (communicate), penyandi balik (decoder), atau khalayak (audience), pendengar (listener), penafsir (interpreter), yaitu orang yang menerima pesan dari sumber. (e) Efek. Apa yang terjadi pada penerima setelah menerima pesan yang disampaikan (Mulyana, 2011) Dalam penelitian ini, peneliti juga menggunakan model komunikasi dari Lasswell yang berisikan ungkapan verbal yaitu : siapa mengatakan (who 
says), mengatakan apa (says what), kepada siapa (to whom),melalui saluran apa (in which channel), dan dampaknya apa (to what effect). Sumber : Werner J. Severin W. Tankard (dalam Wiryanto, 2004)

\section{Komunikasi Pemerintah.}

Pengertian dari komunikasi pemerintah adalah "the role, practice, aims, and achievements of communication as it takes place in and on behalf of public institution(S) whose primary end is executive in the service of political retionale, and that are constittuted on the basis of the people's indirect or direct consent and charged to enact their will" (Canel \& Jose, 2013).

\section{Strategi Komunikasi.}

Menurut Martin-Anderson dalam Cangara (2014) menyatakan bahwa strategi adalah seni dimana melibatkan kemampuan inteligensi dalam membawa setiap sumber daya yang tersedia untuk mencapai suatu tujuan tertentu dengan memperoleh keuntungan yang efektif dan efisien. Dalam rangka mencapai tujuan tersebut, sebuah strategi harus bisa menunjukkan bagaimana cara mengoperasionalkannya. Oleh karenanya, seorang pakar perencanaan komunikasi Middleton dalam Cangara (2014) merumuskan bahwa strategi komunikasi merupakan kombinasi dari setiap elemen yang ada mulai dari siapa pengirimnya, pesannya apa, saluran media, siapa penerimanya sampai pada pengaruhnya memang disiapkan untuk mencapai tujuan yang maksimal.

Strategi menurut Effendy adalah perencanaan (planning) dan menajemen (management) untuk mencapai suatu tujuan., namun strategi tersebut hanya untuk menunjukan bagaimana taktik operasionalnya. Effendy juga menjelaskan bahwa strategi komunikasi merupakan paduan rencana komunikasi (communication planning) dengan manajemen komunikasi (communication management) untuk mencapai tujuan yang telah ditetapkan dan strategi komunikasi harus mampu menunjukan bagaimana operasionalnya secara praktis harus dilakukan atau bisa dikatakan pendekatan bisa berbeda - beda bergantung pada situasi dan kondisi (Effendy, 2009)

\section{Konsep Public Relations atau Humas}

Public relations atau hubungan masyarakat (humas) menurut Frank Jefkins adalah semua bentuk komunikasi yang terencana, baik ke dalam maupun ke luar, antara organisasi dengan seluruh khalayak dalam rangka mencapai tujuan yang spesifik berdasarkan saling pengertian (Jefkins:, 2004). Kemudian, Institute of Publik Relations (IPR) menyebutkan public relations adalah keseluruhan upaya yang dilakukan secara terencana dan berkesinambungan dalam rangka menciptakan dan memelihara niat baik (good will) dan saling pengertian antara suatu organisasi dengan segenap khalayaknya" (dalam Sularso, Komunika : Warta Ilmiah Populer Komunikasi dalam Pembangunan). 
Menurut Perhimpunan Masyarakat PR Amerika (The Public Relations Society of America/ PRSA) adalah : "Public relations is the distinctive management and maintain mutual lines of communication, understanding, acceptance, and cooperation between an organization and its publics; involves the management of problem issue; helps management to informed on and responsive to public opinion; defines and amphasizes the responsibility of managementto serve the public interest; helpes management keep abreast of and effectively utilize change, serving as an early warning system to help anticipate trends and user research and sound ethical communication as its principal tools" (dalam Sularso, Komunika : warta ilmiah populer komunikasi dalam pembangunan).

Menurut John E. Marston dalam bukunya Public Relations (New York : Mc Graw-Hill, 1979) menyatakan, "Public relations is planned, persuasive communication designed to influence significant public".

Dengan demikian, maka public relations atau hubungan masyarakat adalah suatu bidang yang memerlukan segi perencanaan yang matang (planned), yang dapat dikatakan sama seperti bidang periklanan yang melakukan "komunikasi", yaitu gabungan antara melakukan komunikasi dan sekaligus membujuk (persuasive). Ruslan juga mengatakan bahwa dalam (PR Campaign and Propaganda) selain untuk mengkampanyekan program kerja, aktivitas dan informasi tujuan lainnya adalah untuk memperkenalkan, meningkatkan kesadaran atau pengertian dan mencari dukungan publik dari sasaran khalayak (target audience) dan sekaligus mempengaruhi serta membujuk sasaran khalayak yang terkait dan dituju (significant public), perkembangan berikutnya dikenal dengan khalayak sasaran (stake holder) yang terkait (Ruslan, 2007).

Peran dan Tujuan Public Relations. Menurt Ruslan (2007) dalam buku Kiat dan Strategi Kampanye PR menyimpulkan bahwa peran utama public relations adalah sebagai berikut : (a) Sebagai penghubung antara organisasi atau lembaga yang diwakili dengan publik (communicator). (b) Membina hubungan positif dan saling menguntungkan dengan pihak publiknya (Relationship) (c) Peranan sebagai pendukung dalam fungsi manajemen organisasi atau perusahaan. (back up management) (d) Membentuk citra bagi organisasi atau lembaganya (corporate image).

Fungsi Public Relations Perusahaan. Maria di dalam buku Komunikasi dan Public Relations (Kadar Nurjaman \& Khaerul Uman, 2012) menyebutkan "Public Relations merupakan suatu bagian dari satu nafas yang sama dalam organisas/lembagai, dan harus memberi indentitas organisasinya dengan tepat dan benar, serta mampu mengkomunikasikannya dengan baik sehingga publik menaruh kepercayaan dan mempunyai pengertian yang jelas dan benar terhadap organisasinya tersebut".

Dengan penjelasanan di atas dapat digambarkan bahwa fungsi dari public relations adalah : (a) Kegiatan untuk mendapatkan itikad baik, kepercayaan, pengertian dan citra yang baik dari publik. (b) Publik menjadi sasaran untuk menciptakan opini publik yang 
menguntungkan publik dan perusahaan. (c) Fungsi manajemen yang yang lebih spesifik dalam mewujudkan tujuan perusahaan sesuai dengan harapan publik dengan identitas perusahaan kekhasan perusahaan. (d) Menciptakan hubungan baik antara publik dan perusahaan, yang dimana opini publik merupakan input bagi perusahaan.

Strategi Public Relations. Menurut Nova (2011) dalam buku Crisis Public Relations membahas fungsi strategi komunikasi Public Relations (PR) atau Humas yang sebelumnya pernah dituliskan dalam Ruslan (2003) sebagai berikut: (a) Publikasi. Fungsi dan tugas PR adalah untuk menyelenggarakan publikasi atau menyebarkan informasi tentang kegiatan suatu organisasi yang patut untuk diketahui publik, selain itu meciptakan suatu berita agar mendapatkan publisitas bekerjasama dengan media atau pers agar menguntungkan citra organisasi/lembaga yang diwakilkan. (b) Event. Membuat acara atau event untuk memperkenalkan produk atau layanan suatu organisasi/lembaga dengan tujuan mendekatkan diri kepada publik dan diharapkan dapat mempengaruhi opini publik. Jenis-jenis acara atau event yang biasa dilakukan oleh seorang PR adalah sebagai beikut : 1) calender event, 2) special event, dan 3) moment event. (c) Berita, Membuat berita melalui press release, news letter, bulletin, dan lain sebagainya sehingga hal tersebut menuntut seorang PR memiliki kemampuan untuk menulis atau menciptakan publisitas. (d) Community involvement, Mengadakan kontak sosial dengan kelompok masyarakat tertentu untuk menjaga hubungan baik (community relations and humanity relations) dengan pihak organisasi atau lembaga yang diwakilinya. (e) Inform or image, Dua fungsi utama PR yaitu meberikan informasi kepada publik atau menarik perhatian sehingga diharapkan dari informasi tersebut mendapatkan tanggapan berupa citra positif. (f) Lobbying and negotiations, Keterampilan untuk melakukan pendekatan pribadi dan kemampuan bernegosiasi agar mencapai kesepakatan (deal) atau memperoleh dukungan dari individu dan lembaga yang berpengaruh terhadap kelangsungan bisnis perusahaan. (g) Social responsibility. Memiliki tanggung jawab sosial dalam aktivitas PR akan menunjukan bahwa peruahaan memiliki kepedulian terhadap masyarakat, sehingga cara ini dapat meningkatkan citra perusahaan di mata publik (Nova, 2009).

\section{SIPA Mahaswara}

SIPA Mahaswara kepanjangan dari Solo International Performing Art (SIPA) Mahaswara disingkat SIPA Mahaswara, yaitu sebuah ajang pergelaran seni pertunjukan yang berisikan materi seni tari, musik, dan teater yang digelar sejak tahun 2009. Tahun 2016 penyelenggaran SIPA bertemakan Mahaswara. Tema Mahaswara mengandung makna menyampikan pesan kemanusiaan yang akan ditebarkan melalui keindahan seni pertunjukan ke berbagai bangsa dari penjuru dunia. Dunia membutuhkan swara atau suara, terutama yang berhubungan dengan suara kemanusiaan; seperti tentang perdamaian, pelestarian alam, dan persahabatan. Melalui SIPA 2016, spirit Maha Swara akan diungkapkan melalui seni pertunjukan khususnya tari, dan musik, sehingga dapat dibayangkan bagaimana kemegahan dan keindahan Maha Swara itu ketika berada dalam panggung SIPA (sipafestival.com). 


\section{METODE PENELITIAN}

Jenis penelitian ini menggunakan pendekatan kualitatif. Salah satu karakterisktik penelitian kualitatif adalah deskriptif dimana data yang dikumpulkan berupa kata-kata, gambar, dan bukan angka karena menerapkan metode kualitatif dan semua yang dikumpulkan berkemungkinan menjadi kunci terhadap apa yang diteliti. Melalui metode penelitian ini, peneliti akan memberikan gambaran terhadap keadaan serta fenomena suatu objek yang diteliti secara mendalam dengan melakukan wawancara.

Sumber data dalam penelitian ini diambil dari jenis data yang dikumpulkan dari data primer dan data sekunder. Data primer disini adalah data yang diperoleh peneliti secara langsung dari narasumber sebagai informan yang langsung berhubungan dengan fokus penelitian, sedangkan data sekunder adalah data yang telah dikumpulakn oleh pihak lain, bukan oleh peneliti sendiri untuk tujuan lain, sehingga peneliti hanya sekedar mencatat, mengakses, atau meminta data tersebut ke pihak lain yang telah mengumpulkannya di lapangan (Istijanto, 2009). Dalam penelitian ini, data sekunder yang dikumpulkan peneliti berasal website dari SIPA, flyer, dan social media.

Guna mendapatkan data informasi yang akurat, maka dalam penelitian ini peneliti memilih narasumber yang dianggap mampu memberikan jawaban atas permasalahan penelitian. Oleh karena itu, peneliti mewawancarai 3 orang narasumber dalam penelitian ini adalah: 1) Kepala Dinas Pariwisata Kota Surakarta, 2) Humas Pemerintah Kota Surakarta, dan 3) Ketua Solo Internasional Performing Art.

Teknik analisa data pada penelitian mengenai strategi Humas Pemkot Surakarta dalam mengenalkan SIPA Mahaswara ini menggunakan analisis data Model Interaktif Miles \& Huberman (Sugiyono, 2009). Menurut Miles \& Huberman ada tiga tahapan teknik pengumpulan data dalam aktivitas anailis data, yaitu sebagai berikut : (a) Reduksi data (data reduction). Data yang dicatat secara teliti dan rinci. menganalisis dan merangkum hal-hal yang pokok, memfokuskan pada hal- hal yang penting, dicari tema dan polanya. Dengan tujuan mempermudah peneliti untuk melakukan pengumpulan data selanjutnya dan mencarinya bila diperlukan. (b) Penyajian data (data display). Dilakukan dalam bentuk uraian singkat, bagan, hubungan antar kategori, flowchart sdan sebagainya. Penyajian data penelitian kualitatif adalah dengan teks yang bersifat naratif. (c) Penarikan kesimpulan/verifikasi (conclusion drawing/verification). Langkah selanjutnya dalam analisis data kualitatif menurut Miles dan Huberman adalah penarikan kesimpulan dengan data bukti bukti yang mendukung.

\section{HASIL DAN PEMBAHASAN}


Berdasarkan hasil penelitian mengenai strategi Humas Pemkot Surakarta dalam mengenalkan SIPA Mahaswara, dilakukan pembahasan sebagai berikut:

\section{Stategi Humas Pemkot Surakarta}

Dari hasil analisis wawancara ditemukan bahwa strategi yang digunkaan oleh Humas Pemkot Surakarta untuk mempublikasikan acara SIPA Mahaswara adalah dengan meminimalisir biaya, namun bisa menyebarluaskan potensi yang dimiliki melalui media sosial. Strategi tersebut digunakan karena pihak pemkot menganggap bahwa saat ini masyrakat menggunakan media sosial yang diunggah melalui smart phone masingmasing, sehingga dengan adanya media sosial, informasi dapat tersebar secara luas. Hal tersebut sesuai apa yang disampaikan oleh Martin-Anderson dalam (Cangara, 2014) bahwa strategi adalah seni dimana melibatkan kemampuan inteligensi/pikiran dalam membawa setiap sumber daya yang tersedia untuk mencapai suatu tujuan tertentu dengan memperoleh keuntungan yang efektif dan efisien.

Meskipun Pemkot Surakarta dalam mempublikasikan tidak fokus pada satu kegiatan melainkan mempublikasikan keseluruhan acara yang dimiliki termasuk SIPA Mahaswara. Jika dikaitkan dengan strategi humas yang dituliskan oleh Nova pada tahun 2011, strategi humas yang dilakukan oleh Pemkot Surakarta dikaitkan dengan 5 poin, yaitu :

Publication, Pemkot Surakarta dalam melakukan publikasi tidak fokus hanya pada satu kegiatan melainkan untuk keseluruhan acara yang dimiliki. Salah satu media yang digunakan adalah buku calender of event yang berisikan 57 kegiatan rutin setiap tahunnya dan acara SIPA Mahaswara termasuk dalam buku tersebut. Selain itu, pihak pemkot juga menggunakan papan pengumuman untuk setiap bulannya yang berisikan jadwal kegiatan yang diletakan di setiap hotel yang ada di Solo. Pihak Pemkot Surakarta juga memaksimalkan penggunaan media sosial sebagai media untuk menyebarluaskan informasi kegiatan.

Humas Pemkot Surakarta juga menggunakan press release untuk memberikan gambaran kepada media yang hadir dalam konferensi pers. Press release dibagikan agar media masa memiliki gambaran untuk mengulas informasi lebih mendalam. Pihak humas SIPA dalam pembuatan berita juga menggunakan press release yang disebarkan kepada seluruh media. Selain itu, humas SIPA juga mengangkat issue yang menarik media masa penasaran dan tertarik untuk meliput kegiatannya.

Special event, SIPA Mahaswara merupakan salah satu kegiatan special event yang dimiliki oleh Pemkot Surakarta. Dikatakan sebagai special event karena acara tersebut merupakan sebuah acara kebudayaan dengan taraf internasional yang diadakan di Kota Solo. Acara tersebut juga merupakan Satu-satunya acara yang dimiliki dan berbeda dari acara-acara lainnya yang ada di Pemkot Surakarta. 
Citra korporasi (corporate identity), melalui kegiatan publikasi yang telah dilakukan, Pemkot Surakarta ingin menunjukkan Solo sebagai kota budaya seperti yang ada di visi dan misi. Humas Pemkot Surakarta menjelaskan bahwa arti budaya yang dimaksud memiliki arti luas tidak hanya kesenian ataupun tarian saja., melainkan unsur budaya lainnya. Kegiatan budaya dapat dilihat dari buku calender of event yang berisi tentang 57 kegiatan yang diadakan oleh Pemkot Surakarta dan mayoritas dari kegiatan itu merupakan kesenian dan kebudayaan yang dimiliki oleh kota Solo seperti salah satunya acara SIPA Festival Mahaswara.

Strategi humas lainnya yang dilakukan oleh Pemkot Surakarta adalah tanggung jawab sosial (social responsibility) dalam aktivitas PR, Kegiatan humas melalui publikasi tersebut, merupakan wujud social responsibility pemkot Surakarta untuk meningkatkan perekonomian dan menjadikan sebagai sumber daya yang dimiliki oleh Kota Surakarta. Kemudian, untuk masyarakat terutama yang memiliki usaha diharapkan dengan adanya publikasi SIPA Mahaswara yang dilakukan bisa meningkatkan jumlah wisatawan yang datang ke Solo. Dengan banyaknya wisatawan tersebut bisa mempengaruhi pertumbuhan ekonomi yang juga berpengaruh kepada masyarakat kota Solo.

\section{Publikasi SIPA Mahaswara}

Pemkot Surakarta ketika melalukan kegiatan publikasi, terutama mempublikasikan SIPA Mahaswara_menggunakan beberapa media publikasi yang dipilih. Seperti dalam Ruslan, kegiatan publikasi lebih menekankan suatu proses dan teknis untuk mempersiapkan dan menerbitkan media komunikasi demi kepentingan kegiatan atau aktivitas humas dalam upaya penyampaian pesan atau opini, informasi, dan berita.

Meskipun di awal sudah dijelaskan bahwa strategi yang digunakan dalam mengenalkan SIPA Mahaswara lebih menekankan pada penggunaan social media untuk penyebarannya, namun pihak Pemkot Surakarta juga menggunakan media lain untuk publikasi. Media tersebut antara lain adalah brosur, leaflet, poster dan flyer yang disebarkan dan dibagikan di ryang publik, hotel, dan ketika ada event lain yang sedang berlangsung.

Kemudian, pemanfaatan media internal, yang digunakan salah satunya adalah media sosial yang dimiliki oleh Humas Pemkot Surakarta, Dinas Pariwisata Surakarta, dan SIPA. Media sosial yang digunakan yaitu fhoaboak. twitter, instagram dan youtube. Masingmasing media sosial tersebut memiliki pengikut sesuai dari segmen media tersebut. Media internal lain yang digunakan adalah website yang saling terhubung dari website surakarta.go.id bisa terhubung ke web Humas Pemkot Surakarta yaitu PPID kemudian juga bisa terhubung ke website Dinas Pariwisata. Selain website yang dimilik Pemkot Surakarta, pihak SIPA juga melakukan publikasi melalui website yang dimilikinya yaitu sipafestival. 
Media internal lain yang digunakan yaitu calender of event yang dikeluarkan oleh Dinas Pariwisata, buku tersebut berisikan 57 kegiatan yang diadakan dalam satu tahun dan salah satunya termasuk SIPA. Selain itu juga ada papan pengumuman yang dikeluarkan oleh Dinas Pariwisata juga, papan pengumuman tersebut diletakkan di hotel-hotel yang ada di Solo dan berisikan rangkaian acara yang akan dilakukan setiap satu bulan. Media lain yang dimiliki ada aplikasi solo destination, aplikasi tersebut berisikan tentang kegiatan yang dimiliki oleh Pemkot Surakara beserta destinasi dan kuliner yang dimiliki. Namun kelemahan dari aplikasi tersebut adalah hanya dapat di download melalui adroid saja.

Media publikasi lain yang digunakan adalah press release. Media tersebut dikeluarkan oleh Humas Pemkot Surakarta dan humas SIPA yang disebarkan kepada media masa.

\section{Hambatan dalam Publikasi}

Pihak humas SIPA dan Pemkot Surakarta menjelaskan bahwa hambatan dalam melakukan publikasi SIPA Mahaswara adalah jika pihak dari pemkot meminta hasil yang lebih baik dari sebelumnya, namun tidak seimbang dengan apa yang dilakukan oleh pihak Pemkot Surakarta. Oleh karenanya, pihak humas SIPA meniiliki anggapan bahwa jika pihak humas SIPA memberikan hasil yang lebih dari sebelumnya, tanggungan yang akan diberikan oleh pihak Pemkot Surakarta akan berkurang.

Namun berbeda dengan hambatan yang dirasakan oleh pihak Dinas Pariwisata dalam melakukan publikasi. Pihak Dinas Pariwisata merasa bahwa diperlukan konsistensi dalam penentuan tanggal, dan itu harus dipikirkan secara matang-matang dalam penetuan tanggal. Buku calender of event dikeluarkan setiap akhir tahun menuju ke awal tahun. Terkadang ketika berjalannya waktu terdapat perubahan tanggal yang tidak dapat diperkirakan dari berbagai faktor. Sehingga pihak Dinas Pariwisata benar-benar memastikan pada seluruh pihak pelaksana untuk benar-benar memastikan tanggal yang akan digunakan agar tidak terjadi perubahan dalam pelaksanaan.

\section{SIMPULAN}

Berdasarkan pembahasan yang diuraikan mengenai strategi Humas Pemkot Surakarta dalam mengenalkan SIPA Mahaswara, maka dapat disimpulkan sebagai berikut:

1. Humas Pemkot Surakarta ternyata tidak berjalan sendiri dalam menjalankan kegiatan publikasi. Humas Pemkot Surakarta melakukan pembagian tugas dalam menjalankan kegiatan publikasi, yaitu bekerja sama dengan tim SIPA di bawah naungan Dinas Pariwisata. Pihak humas Pemkot Surakarta hanya bertugas untuk membantu menyebarluaskan informasi terkait event tersebut dan juga bersedia menjadi fasilitator dalam proses kegiatan publikasi jika memang dibutuhkan. Peran fasilitator 
tersebut salah satunya adalah kegiatan konferensi pers, menyediakan press release, mengundang media, dan mengundang narasumber terkait.

2. Dalam mempublikasikan SIPA Mahaswara, strategi yang digunakan oleh Pemkot Surakarta adalah dengan mengefisiensi biaya namun bisa menyebarkan potensi yang dimiliki secara luas. Penyebaran informasi potensi yang dimiliki tersebut salah satunya menggunakan media sosial karena dianggap banyak masyarakat saat ini sudah menggunakan smart phone. Dalam strategi humas, publikasi dilakukan dengan berbagai media seperti billboard, brosur, poster, leaflet, calender of event, dan media sosial. Kemudian menggunakan special event, yang salah satunya adalah SIPA Mahaswara karena merupakan sebuah pagelaran budaya yang bertaraf internasional. Dalam pembuatan berita, press release digunakan oleh Humas Pemkot dan SIPA untuk disebarkan kepada para media. Dari kegiatan publikasi yang dilakukan Humas Pemkot Surakarta, citra yang ingin didapat oleh organisasi adalah Solo sebagai Kota Budaya dan salah satunya melalui kegiatan publikasi SIPA Mahaswara. Dari seluruh kegiatan publikasi yang dilakukan Pemkot Surakarta tersebut, merupakan salah satu wujud social responsobility agar menambah jumlah wisatawan ke Solo sehingga perekonomian meningkat dan memberikan pendidikan berupa seni dan budaya kepada warga masyarakat Solo.

3. Secara keseluruhan media publikasi yang digunakan Pemkot Surakarta adalah dengan memaksimalkan penggunaan media sosial. Media tersebut digunakan karena dianggap dapat menyebarkan informasi potensi yang dimiliki secara luas dan efisien termasuk dalam hal biaya. Selain media sosial Pemkot Surakarta juga tetap menggunakan printed media seperti brosur, pamflet, /eaflet, banner, calender of event dan billboard sebagai media yang digunakan untuk mempublikasikan SIPA Mahaswara agar informasi dapat tersebar luas

4. Pemkot Surakarta menggunakan berbagai media seperti brosur, leaflet, poster, flyer, media internal, calender of event, dan press release. Kemudian menggunakan special event, yang salah satunya adalah SIPA Mahaswara karena merupakan sebuah pergelaran budaya yang bertaraf internasional. Kegiatan publikasi yang dilakukan Humas Pemkot Surakarta, melalui kegiatan SIPA Mahaswara terbentuk citra positif Solo sebagai Kota Budaya. Selain itu, dengan mengenalkan SIPA Mahaswara dapat menjadi salah satu daya tarik wisata untuk meningkatkan jumlah kunjungan wisatawan ke Solo.

\section{DAFTAR PUSTAKA}

Beatrix, S. (2007). I Love to Organize.. Jakarta : PT. Gramedia Pustaka.

Butterick, K. (2012). Pengantar Public Relations. Jakarta : Raja Grafindo Persada.

Cangara, H. M. (2014). Perencanaan \& Strategi Komunikasi. Depok : PT. Raja Grafindo Persada. 
Cutlip, S. M. (2007). Effective Public Relations. Jakarta : Kencana Prenada Media Group

Effendy, (2009). Ilmu Komunikasi: Teori dan Praktek. Bandung : PT. Remaja Rosdakarya.

Jefkins, Frank. 2004. Public Relations. Jakarta: Erlangga.

Gregory, A. (2004). Perencanaan dan Kampanye Public Relations. Jakarta : Erlangga

Komarudin. (2014). Reformasi Humas Pemerintah. Jakarta : Ganesindo

Nova, F. (2009). Crisis Public Relations : Bagaimana PR Menangani Krisis Perusahaan. Jakarta : PT. Gramedia Widiasarana Indonesia.

Nova, F. (2011). Crisis Public Relations. Jakarta :PT. Raja Grafindo Persada.

Nurjaman, Kadar \& Uman, Khaerul. (2012). Komunikasi \& Public Relations. Bandung: Pustaka Ceria.

Pemerintah Kota Surakarta. (2016). Peraturan Walikota Surakarta. Walikota Surakarta Provinsi Jawa Tengah.

Prisgunanto, Ilham. (2006). Komunikasi Pemasaran : Strategi dan Taktik. Ciawi - Bogor : Ghalia Indonesia.

Pudjiastuti, W. (2013). Manajemen Special Event. Jakarta : Kementerian Pendidikan dan Kebudayaan

Raco, J.R. (n.d). Metode Penelitian Kualitatif. Jakarta : PT. Gramedia Widiasarana Indoensia

Ridwan. (2016, Juli 16). Solo Dinobatkan Kota Batik Dunia, Rutin Gelar Batik Carnival. http://pojoksatu.id/life- style/2016/07/1 6/solo-dinobatkan-kota-batik-duniarutin-gela r-batik- carnival/3/

Ruslan, R. (2003). Public Relations dan Komunikasi. Kelapa Gading : PT. Raja Grafindo Persada

Sipafestival. (2016). Tentang SIPA. Diperoleh dari: http://sipafestival.com/tentang-sipa.

Sugiyono . (2011). Metode Penelitian Kuantitatif Kualitatif dan R \& D. Bandung : Alfabeta.

Sularso, A. (2006). Komunika : Warta Ilmiah Populer Komunikasi Dalam Pembangunan. Jakarta : Yayasan Obor Indonesia (LIPI).

Wiryanto. (2004). Pengantar Ilmu Komunikasi. Jakarta : PT. Grasindo. 